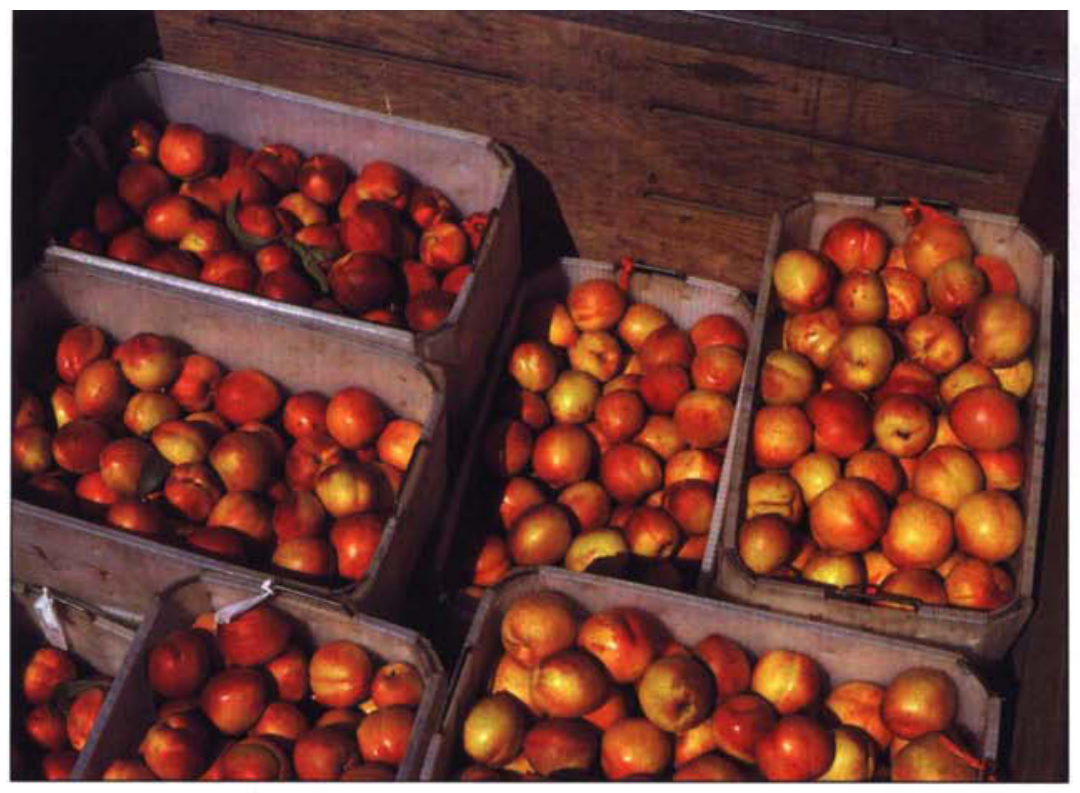

Fruit from trees fertilized with low rates of nitrogen (boxes on the left) ripened earlier and had redder color than fruit from trees fertilized with very high rates of nitrogen. At right, staff research associate Glenn Yokota searches for peach twig borer and oriental fruit moth damage on fruit.

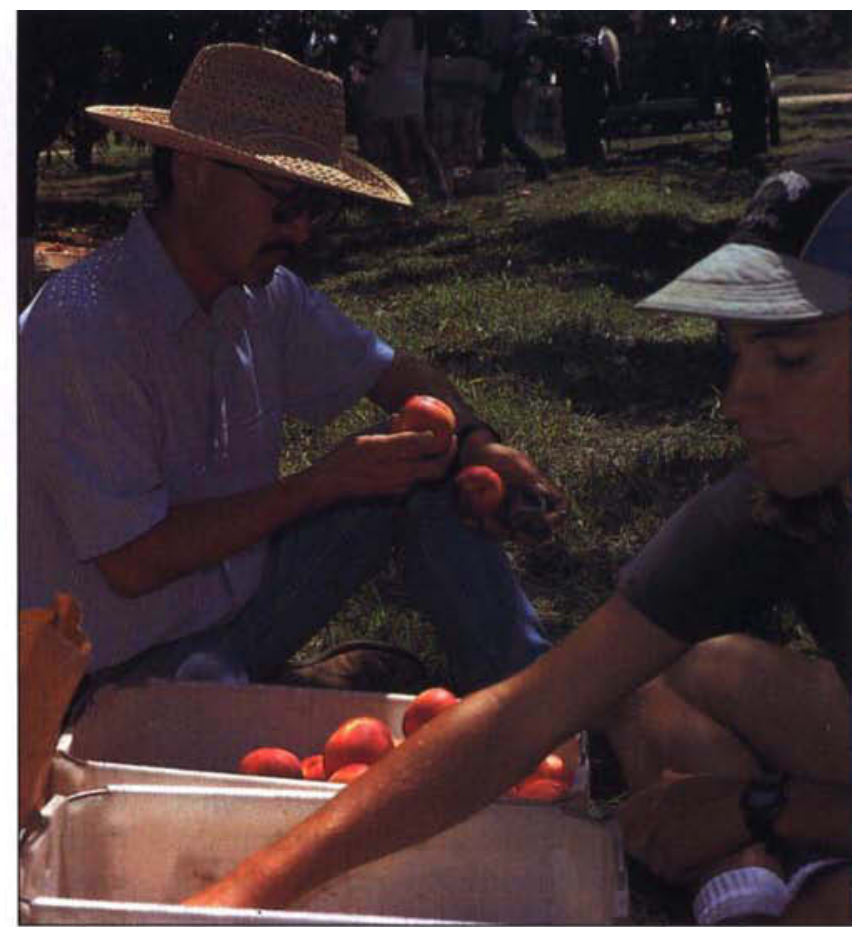

\title{
Excess nitrogen raises nectarine susceptibility to disease and insects
}

\author{
Kent M. Daane a R. Scott Johnson a Themis J. Michailides $\square$ Carlos H. Crisosto \\ Jeff W. Dlott \ Hugo T. Ramirez \ Glenn Y. Yokota \ Dave P. Morgan
}

\section{This multidisciplinary study exam- ined the effects of nitrogen fertili- zation on nectarine yield, fruit} quality, brown rot and moth pests. Results indicate that excess nitrogen fertilization did not increase fruit yield or improve fruit quality; however, fruit on overfertilized trees were more susceptible to attack from brown rot, peach twig borer and oriental fruit moth.

One goal of sustainable agriculture is to reduce chemical inputs, such as pesticides and fertilizers, without decreasing product quality or economic profits. The long-term promise of continued economic gains and environmentally sound management practices offered by more sustainable systems provides incentive to growers to begin the transition process. However, the immediate transition from conventional farm practices, which rely upon some use of synthetic chemicals, to sustainable practices is not always simple. For example, conventional pest management practices can often be broken down into discrete management categories with separate chemical applications for each (one application for fertilization, another for disease pests and still another for insect pests). In contrast, sustainable systems approach farm management as a whole, and practices must work in concert with each other.

One of the building blocks of sustainable systems is soil fertility (Cal. $A g$. Oct-Nov 1994). Growers are often encouraged to lower the input of synthetic nitrogen $(\mathrm{N})$ fertilizers or to use compost or leguminous cover crops to provide the essential $\mathrm{N}$ needed for crop production. Before changes in fertilization practices can be recommended, information must be developed to determine the effects of $\mathrm{N}$ fertilization rates not only on crop yield but also on fruit quality and orchard pest levels. Fertilization practices are also an environmental concern because the $\mathrm{N}$ that is not taken up by plants can be leached through the soil and into groundwater. The problem of excessive $\mathrm{N}$ in groundwater is an increasing concern in California. Every year more wells in California's Central Valley are found to have nitrate levels above the threshold considered to be safe for human consumption.

This article presents work from a 3-year multidisciplinary study that investigated the effect of nitrogen on nectarine yield and quality, postharvest fruit quality and pest management. 

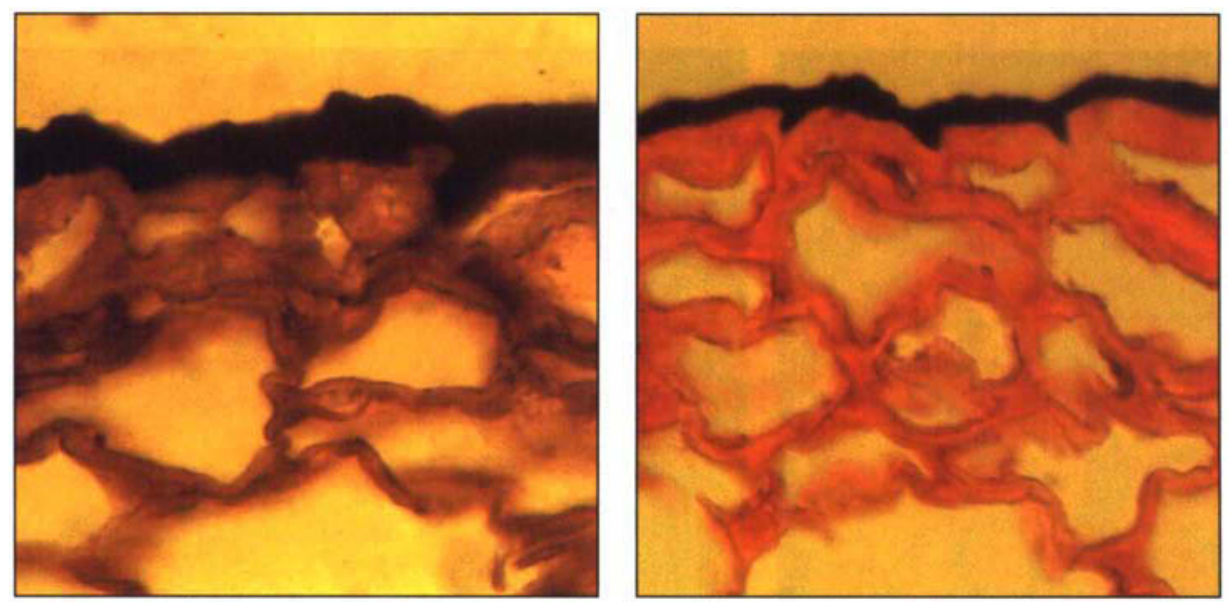

Cross sections of fruit cuticle show the fruit cuticle is thicker in fruit from low nitrogen fertilization treatments, left, than from the higher nitrogen treatments, right. A thicker cuticle may reduce infection of brown rot and improve postharvest characteristics.

\section{Fruit yield and size}

Nitrogen is the main nutrient supplied by fertilizers to nectarine orchards. It is needed to stimulate the growth of fruiting shoots each year to maintain high productivity and large fruit size. Although the majority of stone fruit growers annually apply about 160 pounds of nitrogen per acre (lb N/ac/year), it is not uncommon for individuals to apply 200 to $300 \mathrm{lb}$ $\mathrm{N} / \mathrm{ac} /$ year because they believe this practice will increase crop yields.

However, excess $\mathrm{N}$ fertilization results in overly vigorous growth, which may have a negative effect on fruit quality and may also have deleterious longterm effects on the tree's susceptibility to attack by disease and insect pests.

Methods. To study aspects of $\mathrm{N}$ fertilization on fruit yield and quality, a $\mathrm{N}$ fertilization rate experiment was initiated in a 2-acre block of 'Fantasia' nectarines at the Kearney Agricultural Center in Parlier. The trees were planted in 1975 on a 20-feet-by-20-feet spacing and were trained to an open vase system. We organized five fertilization treatments in a randomized block design, with three replicates each and five trees per replicate. Treatments were an unfertilized control and four $\mathrm{N}$ treatments: 100, 175, 250 and $325 \mathrm{lb} \mathrm{N} / \mathrm{ac} /$ year. The four $\mathrm{N}$ treatments received $100 \mathrm{lb} \mathrm{N}$ as ammonium nitrate broadcast in early September. The latter three treatments then received supplements of ammonium nitrate or calcium nitrate in the spring. All fertilization events were followed immediately with furrow irrigation the irrigation water). The fertilizer treatments were initiated in 1983 and have been maintained since then.

In 1991 and 1992, we collected data to determine the long-term effects of $\mathrm{N}$ fertilization on yield, fruit quality and vegetative growth. Fruit were picked as they matured in two to six separate harvests, over a period of approximately 2 weeks. Total yield was measured for each tree. Average fruit weight was estimated by counting and weighing at least one-third of the total fruit on each tree. Vegetative growth above 10 feet was measured by collecting the prunings removed by a mechanical topping machine in late fall. To determine the effect of vegetative growth on fruit shading, we took light measurements inside the canopy with a Sunfleck Ceptometer (Decagon Inc., Pullman, WA). Leaves were collected from each replicate in early July and sent to the UC DANR Analytical Laboratory for total Kjeldahl $\mathrm{N}$ determination. Soil samples were taken below the root zone ( 7 to 10 feet) in October 1991 and the levels of nitrates determined.

Statistical analyses to separate treatments means were made with Duncan's multiple range test $(P<0.05)$.

Results. In both 1991 and 1992 the trees produced very well; yields and fruit weights were comparable to peak years of production, from 1983 to 1985 . Fertilization rates between 100 and 325 (about $30 \mathrm{lb} \mathrm{N} / \mathrm{ac} /$ year was added by $\mathrm{lb} \mathrm{N} / \mathrm{ac} /$ year resulted in no significant differences in either yield or fruit weight (fig. 1A), whereas in the unfertilized treatment both yield and fruit weight were significantly reduced, as compared to the other $\mathrm{N}$ treatments. This substantiates the conclusion, drawn from earlier studies on shortterm effects, that fertilization rates greater than $100 \mathrm{lb} \mathrm{N} / \mathrm{ac} /$ year did not increase yield or fruit size in the 'Fantasia' nectarine block studied.

Although total yield was not affected by the fertilization treatments above $100 \mathrm{lb} \mathrm{N} / \mathrm{ac} /$ year, the time of fruit maturity was influenced. The higher $\mathrm{N}$ rates significantly delayed commercial maturity by an average of 4 to 5 days, as determined by the number of fruit picked in each harvest and by fruit ground color according to California Tree Fruit Agreement color chips. Also, because the added vegetative growth increased shade inside and beneath the canopy, the total harvest period tended to be longer in the higher $\mathrm{N}$ treatments.

Vegetative growth, as measured by topping weights above 10 feet, also correlated well with $\mathrm{N}$ rate (fig. 1B). However, vegetative growth at the highest $\mathrm{N}$ rate ( $325 \mathrm{lb} \mathrm{N} / \mathrm{ac} /$ year) was significantly lower than at the $250 \mathrm{lb}$ $\mathrm{N} / \mathrm{ac} /$ year rate. The short-term results from this experiment (1985 data) showed that the most vegetative growth occurred with the highest $\mathrm{N}$ treatment. More recent results from the study suggest the possibility of negative effects caused by long-term overfertilization.

Leaf $\mathrm{N}$ levels were correlated with the amounts of $\mathrm{N}$ applied (fig. 2). The results suggest that leaf $\mathrm{N}$ levels higher than $3.0 \%$ indicate excess $\mathrm{N}$ fertilization for 'Fantasia' nectarine. In the nectarine block studied, leaf $\mathrm{N}$ levels between 2.8 and $3.0 \%$ provided sufficient fertilization for optimum crop production, which agrees with the 1985 results from this experiment. Nitrates in the soil samples taken from the 175, 250 and $325 \mathrm{lb} \mathrm{N} / \mathrm{ac} /$ year treatments were substantially higher than those from the unfertilized and $100 \mathrm{lb} \mathrm{N} / \mathrm{ac} /$ year treatments (fig. 2). Therefore the potential for contaminating the groundwater with nitrates in- 
creases substantially when $\mathrm{N}$ is applied at fertilization rates beyond that needed for optimum production.

\section{Postharvest physiology}

Nitrogen fertilization may have a direct influence on postharvest performance by altering fruit nutrient composition, or an indirect effect by influencing firmness, bruising susceptibility and physiological disorders. In pears and apples, it has been well documented that the mineral status of individual fruits affects postharvest life; high-N fruits store poorly. The impact of $\mathrm{N}$ fertilization on nectarine fruit quality and postharvest performance has not been studied in detail, but understanding the influence of $\mathrm{N}$ fertilization is necessary to assure optimal quality and to extend postharvest life. To better determine the relationship between $N$ and postharvest performance, we conducted a series of tests on fruit collected from the 'Fantasia' nectarine block.
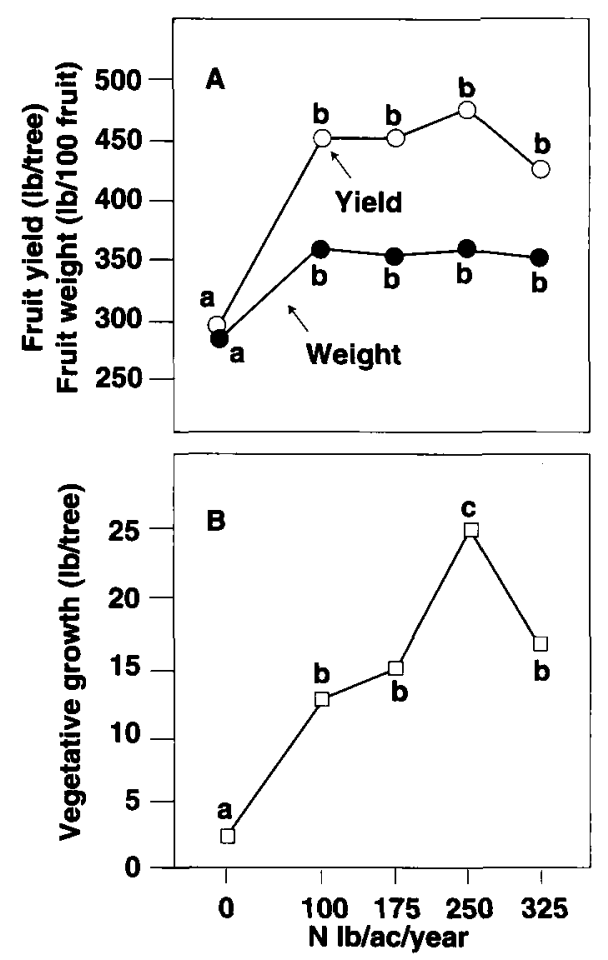

Fig. 1. Effects of nitrogen fertilization treatments on (A) fruit yield and average fruit weight and $(B)$ vegetative growth (over 10 feet). Data averaged for 1991 and 1992 seasons. Treatment means followed by the same letter are not significantly different (Duncan's multiple range test, $P<0.05)$.
Methods. For two seasons, we picked fruit from three different $\mathrm{N}$ levels (0, 175 and $325 \mathrm{lb} \mathrm{N} / \mathrm{ac} /$ year) at commercial maturity, as determined by fruit ground color as measured by California Tree Fruit Agreement color chips. Flesh firmness, $\mathrm{pH}$, titratable acidity, percent red surface color and soluble solids content were measured at harvest time. We also took note of the fruit's postharvest behavior including storage performance (at $32^{\circ} \mathrm{F}$ for 2, 4 and 6 weeks); bruising susceptibility (impact, abrasion and rolling); ripening pattern (softening rate after cold storage); internal breakdown incidence after cold storage; water loss under high water-deficit pressure; and cuticle thickness.

Results. The $\mathrm{N}$ treatments had no effect on most of the postharvest parameters measured, including the harvest measurements of soluble solids content (SSC), $\mathrm{pH}$, titratable acidity (TA), SSC/TA ratio and bruising susceptibility. Internal breakdown and flesh softening after 2, 4 and 6 weeks of storage also showed no difference among treatments.

One measure of fruit quality that was affected by $\mathrm{N}$ fertilization was fruit color. The lower rates of $\mathrm{N}$ induced more red color. Similar results were found during the 1983-1985 evaluation period.

The rate of water loss at $68^{\circ} \mathrm{F}$ and $30 \%$ relative humidity increased proportionately to the amount of $\mathrm{N}$ applied. Also, cuticle isolation studies indicated that cuticle thickness decreased as $\mathrm{N}$ fertilization levels increased. These differences in cuticle thickness might explain the difference in water loss between treatments. The cuticle acts as a barrier to water movement, so when it is thinner, water loss occurs at a faster rate. The results indicate that the lower $\mathrm{N}$ treatments produce higher quality fruit because of the potential for a longer storage life due to lower water-loss rates and because of more red color.

\section{Brown rot}

It has long been recognized that fertilization practices affect levels of plant disease. However, few good examples exist on the effects of $\mathrm{N}$ fertilization on

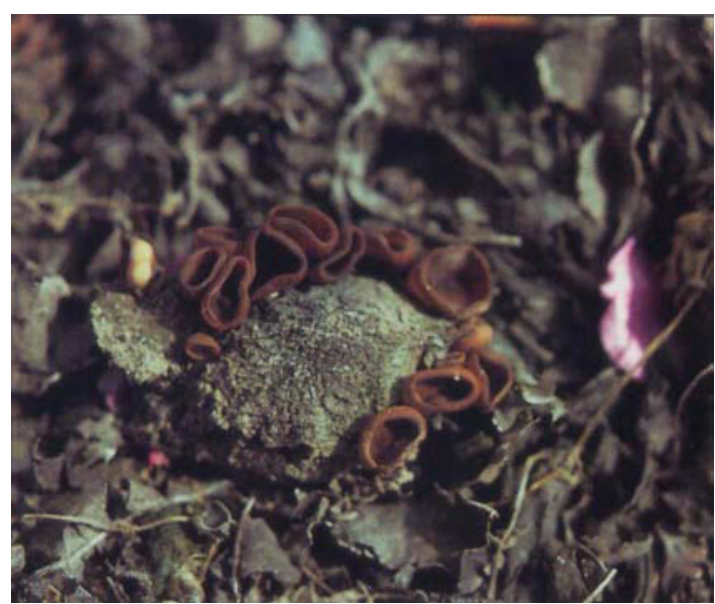

Brown rot apothecia, shown here on a fallen frult mummy, liberate ascospores when the trees are at bloom, causing blossom infections.

brown rot, a major disease of stone fruits caused by the fungus Monilinia fructicola. For this reason, we conducted a series of experiments to study the relationship between $\mathrm{N}$ and brown rot on nectarine blossoms, green fruit and mature fruit from the 'Fantasia' nectarine block described previously.

Methods. To determine the effect of $\mathrm{N}$ fertilization on brown rot in blossoms, on March 1, 3, 5 and 11, 1992, shoots from each treatment replicate were sprayed with a suspension of $2 \times 10^{4}$ or $3 \times 10^{4}$ spores $/ \mathrm{ml}$ of $M$. fructicola and covered with both a plastic bag and a paper bag to increase humidity and induce disease. These doses may be higher than field rates, but were used to obtain a laboratory

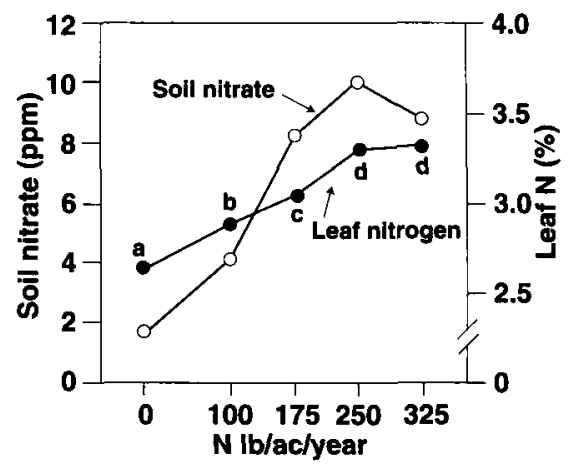

Fig. 2. Leaf nitrogen $(\mathbf{N})$ level and soil $\mathrm{ni-}$ trates in nitrogen fertilization treatments. Leaf $N$ values, averaged for 1991 and 1992 seasons, increased in higher $\mathbf{N}$ treatments. Treatment means followed by the same letter are not significantly different (Duncan's multiple range test, $P<0.05$ ). There were no significant differences in soil nitrates (data collected in October 1991). 


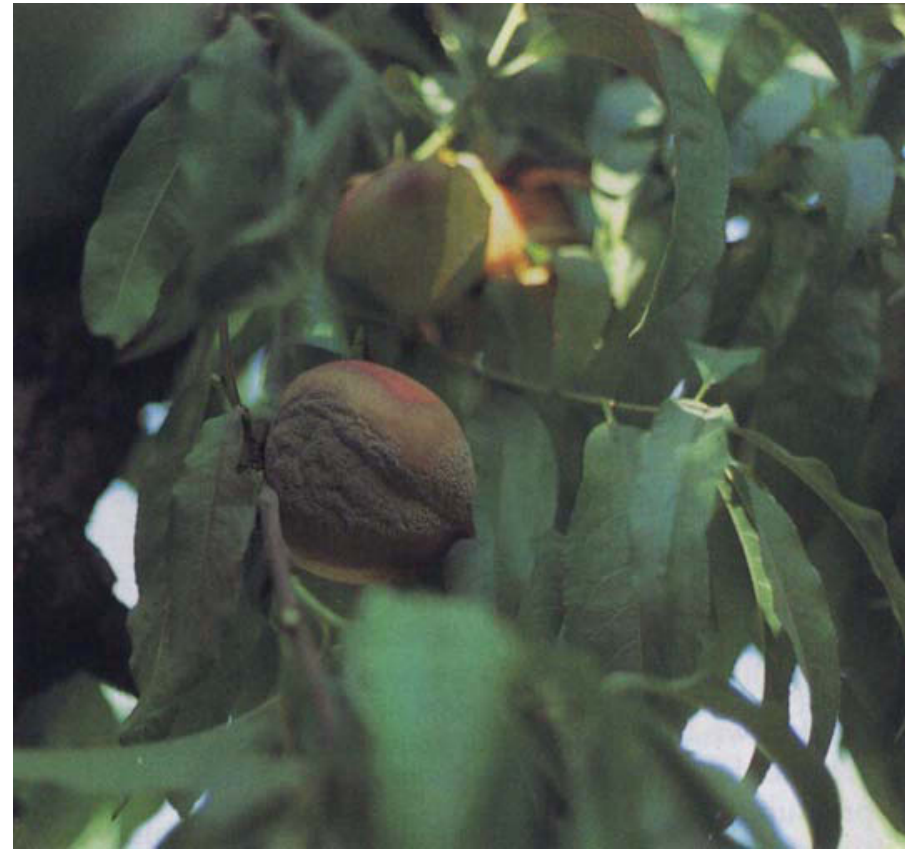

Nectarines infected with brown rot, a major disease of stone fruits caused by the fungus Monilinia fructicola.

response. Spores (also called conidia) are the infective stage of $M$. fructicola. The incidence of infected stamens was recorded 3 days after inoculation.

Our studies on the effects of $\mathrm{N}$ fertilization on green fruit began by inoculating three shoots from each treatment replicate with a $10^{5}$ spores $/ \mathrm{ml}$ suspension. The shoots with inoculated fruit were covered with a plastic bag inside and a paper bag outside. Bags were removed 24 to 48 hours later. The inoculations began on April 4 and continued until July 1 , at $14-$ to 20-day intervals. All inoculated fruit were harvested on July 13, surface disinfected, and incubated in plastic containers to induce decay development.
Severity of disease was determined by counting individual lesions per fruit.

During the commercial harvest time, mature nectarine fruit were collected and incubated under high relative humidity (> 95\%) for 3 days. Lesions of brown rot per fruit were counted. Other batches of mature fruit from each treatment were surface disinfected and then spray-inoculated with $10^{4}, 2 \times 10^{4}$ or $4 \times 10^{4}$ spores $/ \mathrm{ml}$ suspension of $M$. fructicola. After 3 days incubation at $75^{\circ} \mathrm{F}$, the incidence of the disease and number of lesions per fruit were determined.

To examine the cuticle thickness of mature fruit, 10 fruit in each treatment replicate were collected at harvest time, cut into thin sections with a microtome and stained with Sudan Black (a stain specifically for plant cuticles). Thin sections were observed with a compound microscope and photographed. In addition, the weights of cuticle sections $(0.37$ inches in diameter) from 50 fruit in each treatment replicate were determined using a standard chemical procedure.

Brown rot incidence on fruit dropped on the ground was recorded on July 8 and on hanging mummies on

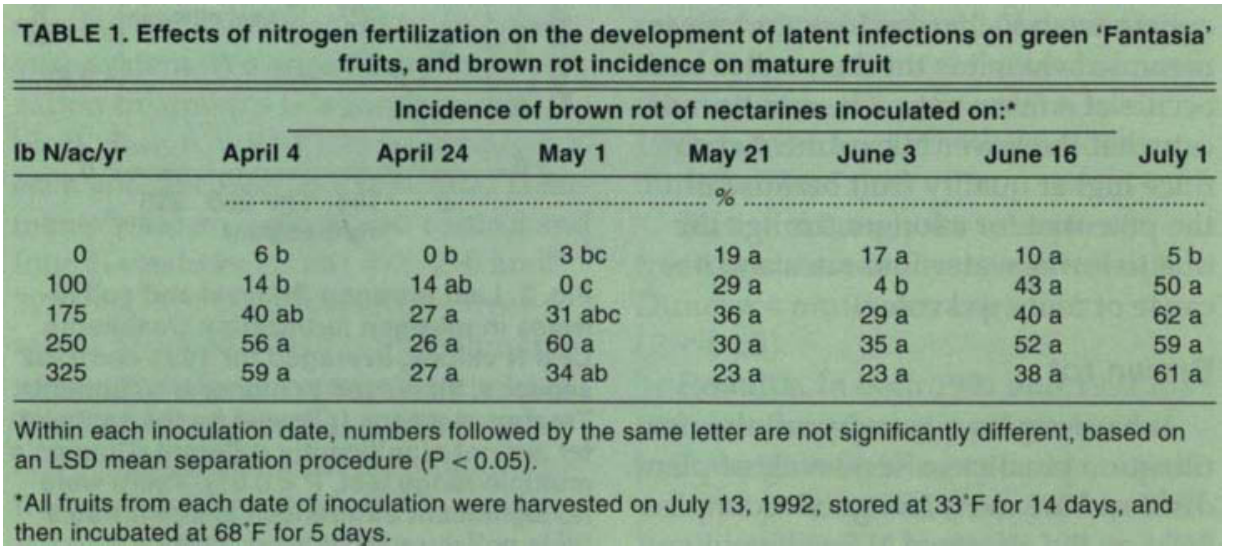

December 9, each on three trees per treatment replicate.

Statistical analyses to separate treatment means were based on an LSD mean separation procedure $(P<0.05)$, and correlations of $\mathrm{N}$ fertilization rates with disease indices were made with linear regression.

Results. Blossoms from unfertilized trees showed the lowest levels of infection. When the data were combined for all infection dates, significantly more stamens were infected from blossoms of the high $\mathrm{N}$ treatments than from blossoms of the unfertilized and $175 \mathrm{lb} \mathrm{N} / \mathrm{ac} /$ year treatments. The difference among $\mathrm{N}$ treatments was greatest in inoculations at full bloom (March 3). Inoculations before and after full bloom (March 1 and 5, respectively) trended toward increased levels of stamen infection with increased $\mathrm{N}$ fertilization levels, but the differences were not significant.

Results of green fruit inoculations, combined over all dates, showed a positive correlation between incidence of infected fruit and $\mathrm{N}$ fertilization. Fruit from trees treated with high $\mathrm{N}$ rates, inoculated on April 4 and 24, May 1 and July 1, had significantly higher incidence of brown rot (table 1). Fruit inoculated on May 21 and June 3 and 16 showed trends toward higher incidence of brown rot on fruit from trees with higher $\mathrm{N}$ treatment levels, but the differences were not significant.

Increased $\mathrm{N}$ fertilization also resulted in increased levels of brown rot incidence in mature fruit (fig. 3). Regardless of the $\mathrm{N}$ levels, the higher spore concentrations resulted in the greatest number of lesions per fruit.

Tests with overwintering mummies showed similar results, with positive correlations between higher $\mathrm{N}$ treatments and infections of $M$. fructicola in both dropped fruit and numbers of mummies hanging on the trees (fig. 4).

As shown in the postharvest studies, the cuticle weight of fruit from the unfertilized control was greater than that from trees fertilized with 100 to $250 \mathrm{lb} \mathrm{N} / \mathrm{ac} /$ year. In addition, thin sectioning indicated that cuticle thickness decreased as $\mathrm{N}$ fertilization increased. High $\mathrm{N}$ fertilization results in 
denser tree canopies, which shade fruit. Shading has been reported as the cause of thinner cuticles in many plants. It is possible that excessive shading of nectarine fruit in the high $\mathrm{N}$ treatment trees prevented the development of nectarine fruit cuticles.

\section{Insect pests}

The oriental fruit moth (OFM), Grapholita molesta, and the peach twig borer (PTB), Anarsia lineatella, are the primary moth pests in California's nectarine and peach orchards. Mating disruption using moth sex pheromones is a viable control option for OFM, and well-timed applications of Bacillus thuringiensis can provide control of PTB. However, orchards with fruit harvested mid- to late season require a second application of pheromones and repeated applications of $B$. thuringiensis, increasing the cost and, in some cases, lowering the effectiveness of these control strategies. Therefore it is still important to promote orchard management practices that either decrease pest abundance or increase natural enemy effectiveness. In on-farm studies, we observed that high levels of OFM and PTB damage occurred in trees that had excessive growth of new foliage and that this shoot growth was correlated with high $\mathrm{N}$ fertilization. We tested this relationship in the 'Fantasia' nectarine block.

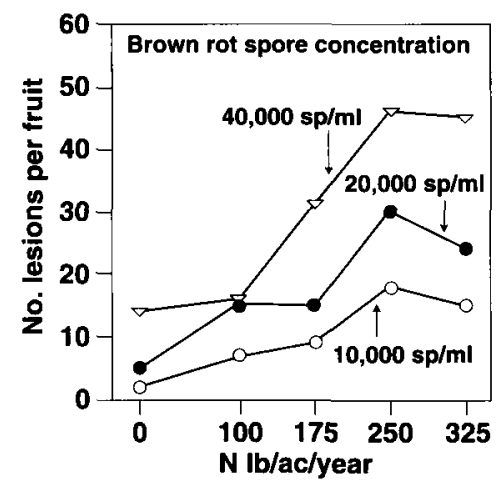

Fig. 3. Effects of nitrogen (N) fertilization treatments and spore concentration of Monilinia fructicola on infection of mature 'Fantasia' nectarines. A positive correlation was found between increased $\mathbf{N}$ fertilization and the number of lesions per fruit at spore concentrations (per $\mathrm{ml})$ of $10,000(y=2.32+$ $\left.0.05 x, r^{2}=0.85, P<0.01\right), 20,000(y=11.062$ $\left.+0.11 x, r^{2}=0.89, P<0.05\right)$, and $40,000(y=$ $\left.6.442+0.07 x, r^{2}=0.78, P<0.05\right)$.
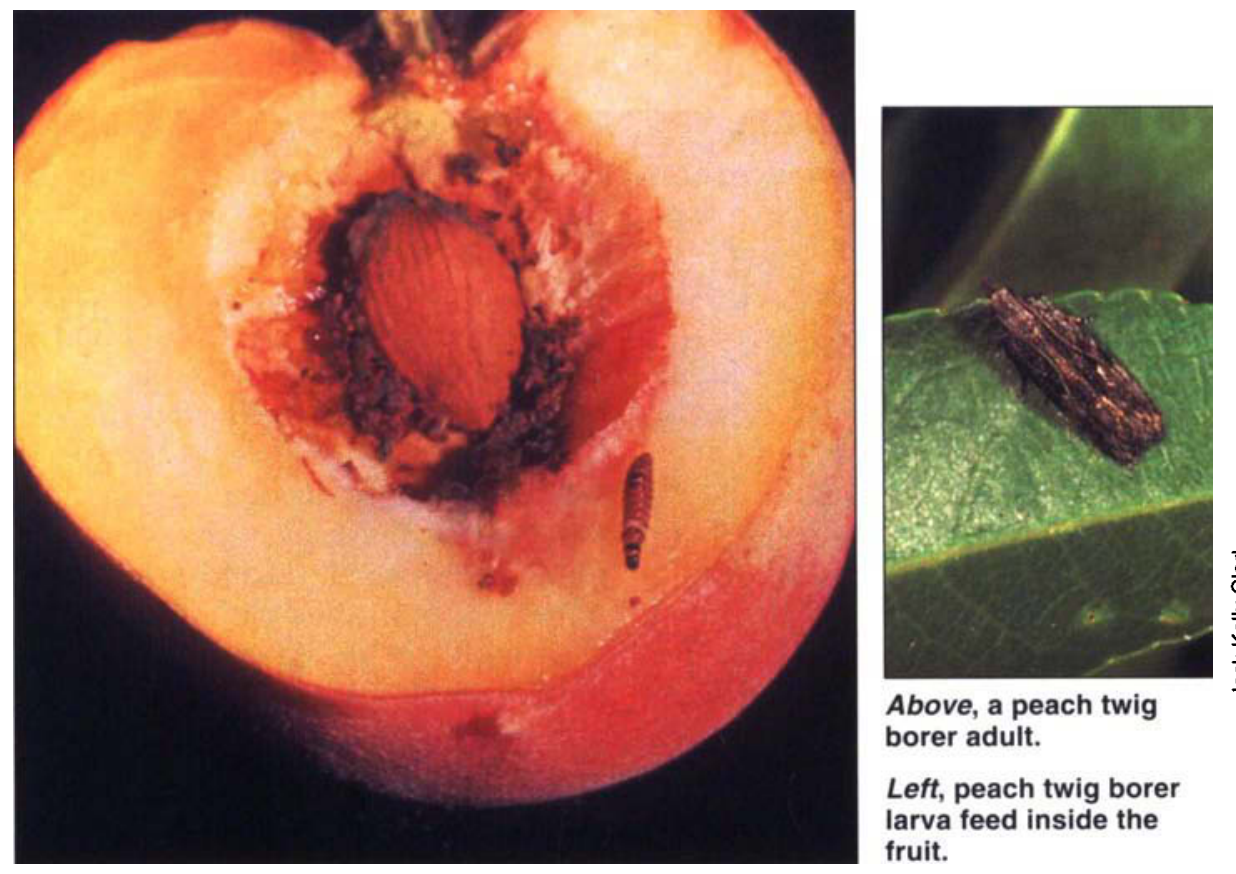

Above, a peach twig borer adult.

Left, peach twig borer larva feed inside the fruit.

Methods. To determine the effect of $\mathrm{N}$ fertilization on fruit damage by insect pests, over 50,000 (1991) and 40,000 (1992) fruit were examined at harvest for damage from PTB, OFM and the omnivorous leafroller, Platynota stultana.

While fruit infestation is the primary cause of economic loss from moth pests, OFM and PTB cannot sustain populations in the orchard without feeding on foliage during the season because suitable fruit is not always available. To determine the effect of shoot condition on PTB larvae, 30 new growing shoots and 30 older shoots

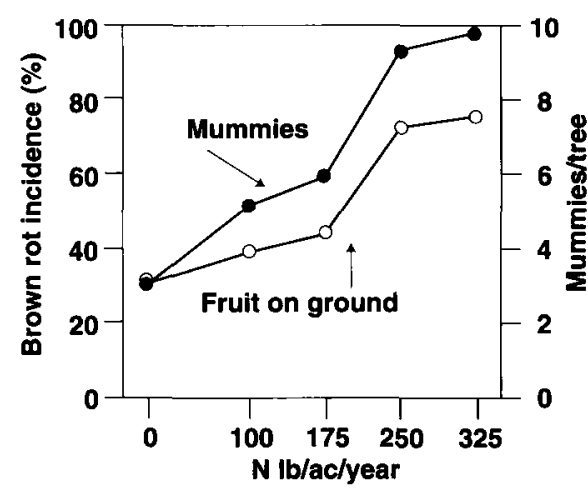

Fig. 4. Effects of nitrogen (N) fertilization treatments on brown rot developed on fruit dropped on the ground and the number of overwintering mummies hanging on 'Fantasia' nectarine trees. A positive correlation was found between increased $\mathbf{N}$ fertilization and the development of brown rot on dropped fruit $\left(y=1.2+0.0085 x, r^{2}=\right.$ $0.89, P<0.05)$ and hanging mummies $(y=$ $\left.2.92+0.022 x, r^{2}=0.98, P<0.01\right)$. were collected. Each shoot was cut under water and placed individually in a growth medium to maintain turgor. A single first-instar PTB larva was placed on each shoot with a camel-hair brush. The success or failure of the larva to infest each shoot was determined after 5 days by dissecting the shoot.

To determine if $\mathrm{N}$ fertilization affected the number of available host sites (new shoots), the number of new and infested shoots was determined from monthly counts in each treatment replicate. Distribution of new and old shoots and shoot strikes in the tree canopy was also determined throughout the season.

Statistical analyses to separate treatment means were made with Tukey's pairwise multiple comparison test $(P<$ 0.05 ), and correlation of $\mathrm{N}$ fertilization rates with infested fruit or shoots were made with linear regression.

Results. Fruit damage by moth pests was significantly greater in the higher $\mathrm{N}$ treatments (fig. 5). Because plot size was small and the adult moths could easily fly between treatments, there are only a few probable explanations for the correlation between $\mathrm{N}$ levels and percent fruit infestation. First, fruit in the higher $\mathrm{N}$ treatments required a longer time to reach maturity, as discussed previously, and this resulted in a greater period of exposure to pests. The increased preharvest period becomes more im- 
portant with cultivars that mature fruit near OFM or PTB adult flight because the moths are more likely to lay eggs directly on the ripening fruit (hard, green fruit are less suitable hosts for OFM and PTB). A second possibility is that the different fruit infestation levels observed may reflect a preferential egg deposition by adult moths on trees and fruit in the higher $\mathrm{N}$ treatments. A third possibility is that characteristics of trees in the higher $\mathrm{N}$ treatments, such as shoot growth, favored moth survival as compared to trees in the unfertilized and lower $\mathrm{N}$ treatments. The latter explanation addresses an important component of the insect/host plant relationship: the suitability of the host site.

Results of the laboratory test showed over $90 \%$ successful entry and feeding of the PTB larvae on new shoots, whereas less than $10 \%$ of the older shoots were infested (t-test, $P<$ $0.0001)$. The data indicate that new shoots provide excellent larval feeding sites, but that as those shoots harden off they are less suitable for PTB feeding. An indication of this relationship was seen in the seasonal distribution of shoot infestations in the canopy. Af-

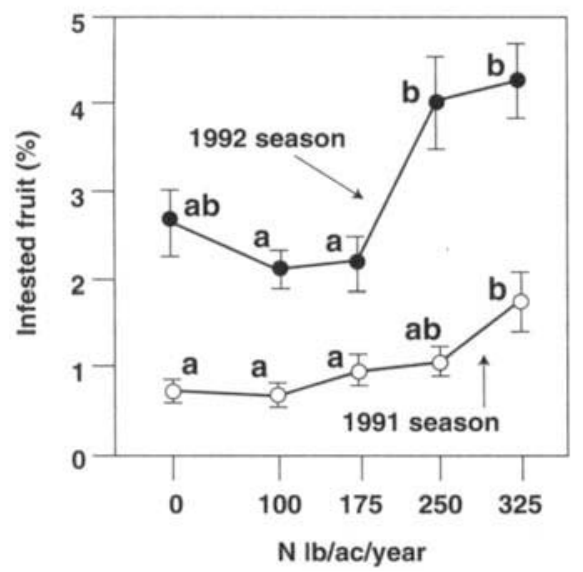

Fig. 5. Relationship between nitrogen (N) treatments and percent fruit infested with peach twig borer and oriental fruit moth for the 1991 and 1992 seasons. A positive correlation was found between increased $\mathrm{N}$ fertilization and infested fruit in 1991 $\left(y=0.78+0.0011 x, r^{2}=0.78, P<0.001\right)$ and $1992\left(y=1.5+0.0007 x, r^{2}=0.67, P<0.001\right)$. In each year, treatment means followed by the same letter are not significantly different (Tukey's multiple pairwise comparison test, $P<0.05)$. Data were transformed $(\sqrt{ }(x+$ $0.5)$ for statistical analysis. ter harvest, OFM and PTB shoot infestations were significantly greater in the upper canopy, where there was a corresponding increase in new shoots.

Thus, nitrogen fertilization affects the relationship between the tree and the moth pests by increasing the amount of vegetative growth, as discussed previously. However, there was a seasonal component in this relationship. There was no significant difference between $\mathrm{N}$ treatments in the number of available or infested shoots early in the season. After fruit harvest the differential effect of $\mathrm{N}$ on vegetative growth resulted in significantly greater numbers of available host sites and infested shoots in the higher $\mathrm{N}$ treatments (fig. 6).

\section{Conclusions}

In the 'Fantasia' block studied, the $100 \mathrm{lb} \mathrm{N} / \mathrm{ac} /$ year rate of fertilization resulted in leaf $\mathrm{N}$ levels of 2.6 to $3.0 \%$ $\mathrm{N}$, which produced sufficient vegetative growth to maintain yields and fruit weights equivalent to higher fertilization rates. Applying higher rates of $\mathrm{N}$ fertilization produced no beneficial effects and would only reduce fruit red color and increase the possi-

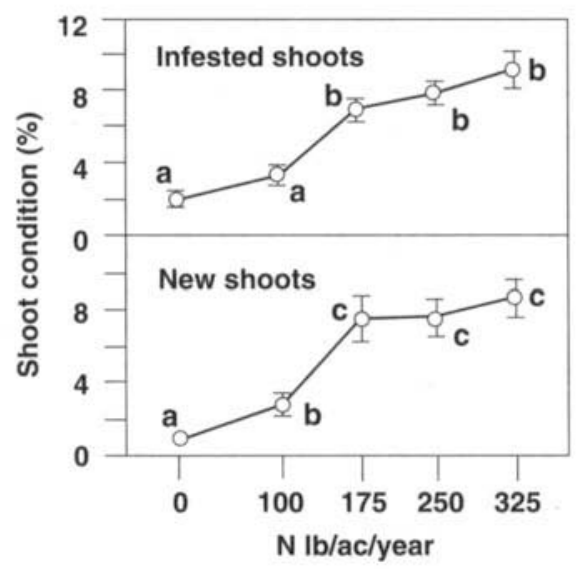

Fig. 6. Relationship between nitrogen (N) treatments and the number of infested ano new shoots. A positive correlation was found between increased $\mathbf{N}$ fertilization and infested $\left(y=1.553+0.347 x, r^{2}=0.42\right.$, $P<0.001)$ and new $\left(y=1.235+0.423 x, r^{2}=\right.$ $0.37, P<0.001$ ) shoots. Treatment means followed by the same letter are not significantly different (Tukey's multiple pairwise comparison test, $P<0.05$ ). Data were transformed $(\sqrt{ }(x+0.5)$, for statistical analysis. bility of leaching nitrates into the groundwater.

The $\mathrm{N}$ treatments had no effect on most of the postharvest parameters measured. Among the parameters that were affected by $\mathrm{N}$ treatments were potential water loss and cuticle thickness, which affect postharvest storage potential and brown rot susceptibility. Nitrogen fertilization was positively correlated with increased levels of brown rot blossom infection. In the higher $\mathrm{N}$ treatments, there was also an increase in the symptomless infections of green fruit (latent infections) and the susceptibility of mature fruit to brown rot. Increased $\mathrm{N}$ resulted in a greater number of fruit dropped and decayed by brown rot and in more mummified fruit hanging on the trees.

Increased $\mathrm{N}$ fertilization was also correlated with greater OFM and PTB fruit infestations. We believe that differences in pest densities are primarily attributed to changes in the number of available host sites, especially late in the growing season. The increase in PTB and OFM survival in August and September represents an increase in the overwintering population and potential damage to next season's crop.

K.M. Daane is Associate Specialist, Laboratory of Biological Control, UC Berkeley; R.S. Johnson is Extension Specialist, Department of Pomology, UC Davis; T.J. Michailides is Associate Plant Pathologist, Department of Plant Pathology, UC Davis; C.H. Crisosto is Postharvest Physiologist, Department of Pomology, UC Davis; J.W. Dlott is Lecturer and Assistant Specialist, Laboratory of Biological Control, UC Berkeley; H.T. Ramirez is Field Station Specialist, Agricultural Products Department, E.I. du Pont de Nemours \& Co.; G.Y. Yokota is Staff Research Associate, Laboratory of Biological Control, UC Berkeley; and D.P. Morgan is Staff Research Associate, Department of Plant Pathology, UC Davis. (All researchers are stationed at the Kearney Agricultural Center.) Funding was provided by grants from the California Tree Fruit Agreement, the California Cling Peach Advisory Board, the University of California Statewide IPM Project and the Western Regional Sustainable Agricultural Research and Education (SARE). 